\title{
Det norske dødsårsaksregisteret: En kommentar til datakvaliteten
}

\author{
Ved Latha Nrugham og Lars Mehlum
}

\begin{abstract}
Nasjonale registre er en verdifull informasjonskilde og et grunnlag for utformingen av både helsepolitikk og nasjonale helseprogrammer. Det er derfor svært viktig at disse registrene har en høy datakvalitet. Det nasjonale Dødsårsaksregisteret er av spesiell interesse for fagfeltet suicidologi.
\end{abstract}

Informasjon om det norske dødsårsaksregisteret er offentlig tilgjengelig på nettsidene til driverorganisasjonen - Statistisk sentralbyrå - og til eierorganisasjonen - Nasjonalt folkehelseinstitutt. Med denne artikkelen $\varnothing$ nsker vi å diskutere noen av forutsetningene for pålitelig dødsårsaksstatistikk generelt og datakvaliteten i det norske dødsårsaksregisteret spesielt. Vi vil først si litt om opprinnelsen til og formålet med registeret. Dernest vil vi beskrive hvordan dødsårsaker kodes i registeret. Til slutt vil vi peke på mulige feilkilder, som definisjon og klassifikasjon av selvmord, og på hvordan disse kan forbedres så vi får en mer nøyaktig selvmordsstatistikk.

\section{Opprinnelsen til og formålet med dødsårsaksregisteret}

I Norge blir alle d $\varnothing$ dsfall registrert, og dødsårsakene blir kodet i henhold til Verdens helseorganisasjons (WHO) diagnosemanual International Classification of Diseases (ICD). Leger er pålagt å rapportere dødsfall gjennom et standardisert dødsattestskjema. Denne informasjonen blir registrert i dødsårsaksregisteret og lagret for hvert individ etter fødselsnummer. Dødsårsaksregisteret lagrer informasjon om alle $\mathrm{d} \varnothing \mathrm{dsfall}$ blant alle personer dokumentert som norske statsborgere eller med fast opphold i Norge på tidspunktet for d $\varnothing$ dsfallet, uavhengig av om de døde i Norge eller ikke. Forutsatt at nødvendige tillatelser foreligger, kan dødsårsaksregisteret kobles mot andre norske registre over individdata. Dødsårsaksstatistikk blir publisert årvisst av Statistisk sentralbyrå, og blir årlig rapportert til The Nordic Medical Statistical Committee (NOMESCO), Eurostat, OECD (Organisation for Economic Co-operation and Development) og WHO.
Dødsårsaksforskriftens $§ 1-3$ sier at formålet med dødsårsaksregisteret er å:

1. overvåke dødsårsaker og belyse endringer i dødsårsaker over tid,

2. gi grunnlag for utarbeidelse av nasjonal, regional og lokal dødsårsaksstatistikk,

3. fremme og gi grunnlag for forskning, og

4. gi grunnlag for informasjon og kunnskap for planlegging, kvalitetssikring og kvalitetsutvikling av helsetjenesten og helseforvaltningen.

Dødsårsaksregisteret er ett av syv sentrale helseregistre i Norge som er etablert for å oppfylle Helseregisterloven (LOV2001-05-18-24). Dødsårsaksregisteret blir driftet av Statistisk sentralbyrå, som produserer alt innholdet, mens Nasjonalt folkehelseinstitutt eier registeret. Et slikt eierskap gjør det lettere å koble registeret til de andre registrene Folkehelseinstituttet eier.

Statistisk sentralbyrå har hatt ansvar for produksjonen av d $\varnothing$ dsårsaksstatistikk helt siden 1922. I 1951 begynte man å klassifisere dødsårsaker i henhold til WHOs ICD-standard. Fra 1996 har man fulgt den tiende revisjonen av ICD (ICD-10).

I 2005 tok Norge i bruk en halvautomatisk versjon av kodesystemet Automated Classification of Medical Entities

(ACME). Det ble utviklet av The US National Center for Health Statistics (NCHS) på 1970-tallet. ACME er et automatisk system for koding av det som er registrert som underliggende dødsårsak på d $\varnothing$ dsattestene. Kodingen er basert på internasjonale regler og overenskomster nedfelt i ICD. Målet med å bruke ACME er å oppnå en mer ensartet kodepraksis på tvers av landegrensene. Dette skal gi bedre og mer sammenlignbar statistikk internasjonalt. EUs statistikkbyrå Eurostat anbefaler bruk av ACME, og alle de nordiske landene bruker nå dette systemet. Dødsårsaksregisteret samarbeider med de nordiske landene via Nordisk senter for klassifikasjoner i helsetjenesten i Oslo. Registeret samarbeider også gjennom WHO for å $\varnothing$ ke sammenlignbarhet og ensartethet i kodepraksisen. Fire ganger i året sammenligner man kodepraksisen i de ulike land med ACME som den internasjonale standard. De siste tallene for raten for overensstemmende koding viser at Norge ligger på omtrent $70 \%$. Statistisk sentralbyrå har ikke gitt noen offisiell kommentar til dette tallet.

En rekke unders $\varnothing$ kelser er gjort av validiteten av selvmordsstatistikk (Burrows \& Laflamme, 2007; Phillips \& Ruth, 1993; O'Caroll, 1989; Jobes et al., 1987). Den generelle konklusjonen fra slike studier er at d $\varnothing \mathrm{d}$ ved selvmord mest sannsynlig blir underrapportert fordi selvmord fortsatt er tabu eller fordi selvmord blir feilklassifisert som ulykke eller ukjent dødsårsak. Men forskerne fant at omfanget av slike unøyaktigheter ikke var stort nok til å gjøre statistikken ugyldig.

Denne forskningen har foreslått måter å forbedre selvmordsstatistikken på, som standardiserte rapporteringsmåter (De Leo et al., 2010) og å slå sammen selvmord og ukjent dødsårsak (Speechley \& Stavraky, 1991). I det følgende vil vi fokusere på enkeltaspekter ved produksjonen av selvmordsstatistikk i Norge, og hva som kan gjøres for å forbedre denne statistikken.

\section{Registrering av dødsårsaker}

Dødsfall i Norge blir vanligvis attestert av en lege. En sjelden gang hender det at politiet utsteder dødsattest. Det kan være tilfeller der politiet ikke har grunn til å mistenke noe kriminelt og det er upraktisk å få en lege til dødsstedet. Den lokale skifteretten sender dødsattester utstedt av politiet til kommunelegen i kommunen der dødsfallet har skjedd. 
Hvis dødsfallet ikke har skjedd i avdødes bostedskommune, blir dødsattesten også sendt til kommunelegen i bostedskommunen. Det er kommunelegen som så sender dødsattesten til Statistisk sentralbyrå. To ganger i året blir data fra Folkeregisteret sammenholdt med data fra Dødsårsaksregisteret for å avdekke uoverensstemmelser.

Om Statistisk sentralbyrå får melding om dødsfall uten at det foreligger $\mathrm{d} \varnothing \mathrm{ds}$ attest, tar de kontakt med fylkeslegen som igjen kontakter den aktuelle kommunelegen. Informasjon fra dødsattesten blir sammenlignet med informasjon fra andre kilder - obduksjonsrapporter, fødselsregisteret og lignende. Om Statistisk sentralbyrå finner at dødsattesten er ufullstendig eller ikke har kommet fram, kontakter de den aktuelle kommunelegen direkte. Denne prosessen utføres 3-4 ganger i året. Den medisinske dødsattesten blir også sammenholdt med dødsmeldinger fra de pårørende eller fra sykehjem og lignende. Dette kan tydeliggjøre ufullstendigheter ved begge dokumenter. D $\varnothing$ dsfall der d $\varnothing$ dsattest ikke lar seg oppdrive og man heller ikke har noen annen informasjon, blir registrert med ukjent dødsårsak. Alle disse kvalitetskontrollene kan innebære at man registrerer opp til $20 \%$ flere selvmord enn man ellers ville gjort (Glattre, 1980).

Data om dødsfall blant nordmenn som for kortere tid er bosatt i utlandet blir innsamlet av Utenriksdepartementet eller - i noen tilfeller - av Skattedirektoratet. Disse dødsfallene blir inkludert i statistikken. Vanligvis blir de registrert med ukjent d $\varnothing$ dsårsak. Et $\varnothing$ kende antall norske borgere d $\varnothing \mathrm{r}$ i utlandet, og for mange av dem mangler man informasjon om dødsårsak. I 1996 døde 267 personer i utlandet, mens tallet i 2007 var 382 og i 2008 394. I ni av ti av disse dødsfallene var dødsårsaken ukjent. En av tre av dem som dør i utlandet er under 55 år, og det er grunn til å tro at mange av disse dødsfallene skyldes ulykker (transportulykker, drukning, fallulykker eller dødsfall forårsaket av medikamenter eller narkotika). Statistisk sentralbyrå deltar i interna- sjonalt samarbeid for å forbedre innsamlingen av data om dødsårsaker i utlandet. Alle dødsfall blir inkludert i datagrunnlaget og aggregert på aldersgrupper og kjønn. Data blir ikke publisert på individnivå. Av personvernhensyn blir data ikke publisert dersom en person kan identifiseres indirekte ved å kombinere de ulike variablene.

Den sykdom eller eksterne skadeårsak som satte i gang årsakskjeden som direkte ledet til dødsfallet skal registreres som den underliggende d $\varnothing$ dsårsak. Det kan for eksempel stå "ulykke”. Fra 1996 kan man i tillegg registrere inntil seks årsaker (betingelser som direkte ledet til d $\varnothing \mathrm{ds}$ fallet og medvirkende årsaker), herunder "selvmord". Den umiddelbare dødsårsaken blir definert som den sykdom, skade eller betingelse som direkte førte til dødsfallet, og som var forårsaket av den underliggende dødsårsaken.

\section{Feilkilder}

Den viktigste kilden til usikkerhet i dødsårsaksstatistikken, og den potensielt største feilkilden, er un $\varnothing$ yaktighet eller inkonsistens i legens diagnose og rapportering på dødsattesten. For eksempel kan diagnosen gitt i dødsattesten være feil, eller årsaksrekkefølgen i diagnosen kan være gal. Tilleggsinformasjon og kontakt med legen er derfor av avgjørende betydning for å sikre kvaliteten på informasjonen om dødsårsaker. Andre mulige feilkilder kan være feilaktig tolkning av informasjonen på dødsattestene og inntastingsfeil. Dersom informasjonen på dødsattesten er basert på obduksjon, vil ofte informasjonsgrunnlaget være optimalt, og da $\varnothing$ kes dødsårsaksregistreringens kvalitet. Forskning på gruppen av opiatavhengige fant eksempelvis at to tredeler av avgjørelsene om dødsårsak var basert på obduksjonsrapporter, og dødsårsaksdataene betraktes derfor som relativt sikre (Clausen et al., 2009). Ved dødsfall på grunn av overdoser er prosentandelen som blir obdusert høyere enn det som er vanlig ellers.

Gjentatte ganger er det gjort studier av mulige feilkilder i den norske dødsår- saksstatistikken. I 1987 utkom det et spesialnummer av Acta Psychiatrica Scandinavica med fokus på påliteligheten av skandinavisk selvmordsstatistikk. To artikler handlet om registreringen av selvmord. Den første av disse omhandlet rutiner og praksiser, og den konkluderte med at registreringskjeden i Norge er mer pålitelig enn i andre land, der det gjøres mindre kryssjekking og registrering av tilleggsinformasjon enn i Norge (Hess $\varnothing, 1987)$. Den andre artikkelen handlet om feilkilder, og den konkluderte med at forskjellene i selvmordsrate mellom de skandinaviske landene gjenspeiler reelle forskjeller (Kolmos \& Bach, 1987). Det er verdt å minne om at forskjellen det her refereres til var at Norge hadde den laveste selvmordsraten i Skandinavia (Juel-Nielsen $\&$ Retterst $\varnothing 1,1987)$.

For å redusere potensielle feilkilder så mye som mulig og få en pålitelig selvmordsstatistikk, må minimum tre betingelser være oppfylt. Det er helt grunnleggende at det finnes et konseptuelt rammeverk med gyldige definisjoner som er anvendbare i praksis. Den neste betingelsen er at disse definisjonene utgjør et anvendelig klassifikasjonssystem. Den tredje betingelsen er at det må finnes kompetente fagfolk som kan bruke rammeverket og klassifikasjonssystemet på en stabil og ansvarlig måte.

\section{Definisjoner}

Man er fortsatt ikke blitt enige om en globalt akseptert definisjon av selvmord. Norge bruker som nevnt WHOs klassifikasjonssystem ICD. Dette systemet blir regelmessig revidert, hvilket innebærer at definisjonene bare er gyldige inntil de blir revidert. (Se historikken for disse endringene på http://www.who.int/ classifications/icd/en/.) Det er to betingelser som må være oppfylt for å kunne si med sikkerhet at et dødsfall er et selvmord. For det første må skaden være gjort eller initiert av den avdøde. For det andre må den avdøde ha hatt sin egen $\mathrm{d} \varnothing \mathrm{d}$ som målet for handlingene. Den første betingelsen er langt enklere 
å få bekreftet enn den andre, som i større grad er gjenstand for fortolkning og slutninger ut fra andre fakta. Dette skaper usikkerhet med hensyn til selvmordsstatistikkens pålitelighet. Man må ta i betraktning at selvmord ikke er en sykdom som kan avgrenses klart, men en type menneskelig atferd der det er et stort potensial for variasjon.

\section{Klassifikasjon}

Først klassifiseres skadens art, for eksempel forgiftning med medisiner eller en skade på kraniet. Deretter anføres Ekoder. E står for Eksterne årsaker, det vil si ulykker og skader, selvmord og mord, og andre eksterne dødsårsaker. E-koder brukes for $\mathrm{d} \varnothing \mathrm{d}$ sfall som skyldes skader, forgiftning og vold. Et eget sett med Ekoder brukes når det etter medisinske eller rettslige unders $\varnothing$ kelser fortsatt er uklart om dødsfallet skyldtes en ulykke eller en intensjonelt påført skade som selvmord eller mord. Her ligger kilden til feil i klassifikasjonene. En økende tendens til å bruke "ukjent dødsårsak"kodene kan resultere i en nedgang i selvmordsratene, og vise versa (Beskow, 1974). Dette skaper vanskeligheter når man vil sammenligne rater mellom nasjoner eller innen en nasjon, for klassifiseringspraksisen kan endre seg. På den annen side er det svært vanskelig å skille mellom selvmord på den ene siden og ulykker, som kan være skjulte selvmord, på den andre. I norske unders $\varnothing$ kelser blant utvalgte grupper voksne, som diabetespasienter, har man funnet en underrapportering av selvmord (Skrivarhaug et al., 2006), mens man i studier av dødsfall hos barn har funnet en overrapportering (Grøholt \& Ekeberg, 2003).

\section{Anvendelse}

I definisjonen og klassifikasjonen av dødsårsaker og datakvaliteten i ulike lands dødsårsaksregistre, er følgende faktorer viktige: For det første vil de ressursene som er tilgjengelige for dette arbeidet påvirke praksis og kvalitet. For det andre vil ulike holdninger og verdier influere på dette arbeidet. For det tredje vil den faglige orientering hos dem som

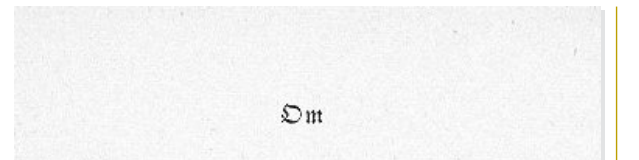

Holdninger og verdier

Der selvmord er sterkt ford $\varnothing \mathrm{mt}$, enten kulturelt eller av offentlige myndigheter ut fra deres ideologi, kultur eller religion, kan hele fenomenet selvmord bli et ikketema og offentlig statistikk kan bli meningsl øs. Danske forskere argumenterte langs slike linjer for at norske selvmord før 1960 ble holdt skjult i mange småsamfunn på grunn av religiøs og/eller sosial ford $\varnothing$ mmelse. Norske forskere har anført som motargument at dansk statistikk kan ha en mangel på systematikk i registreringsprosessen, siden de ikke har gjort de samme kvalitetskontroller som i Norge (Gjertsen, 1987). De har også anført at det vil være vanskelig å skjule selvmord som dødsårsak i småsamfunn med en gjennomsiktig sosial struktur.

\section{Profesjonell orientering}

Hvor strengt klassifikasjonskriteriene for selvmord anvendes, kan variere med ulike fagpersoners profesjonelle orientering. En studie av Ekeberg et al. (1985) sammenlignet diagnostiske vurderinger gjort av personale med ulik profesjonell bakgrunn. Forskerne fant at en psykiater og en koder i Statistisk sentralbyrå bedømte henholdsvis $86 \%$ og $84 \%$ av de studerte tilfellene som selvmord, mens en indremedisiner og en toksikolog kun bedømte $64 \%$ og $60 \%$ av de samme tilfellene som selvmord fordi de brukte kriteriene strengere og kanskje la mindre vekt på omstendigheter og tidligere sykehistorie.

\section{Oppsummering og konklusjon}

Pålitelig selvmordsstatistikk er en svært viktig forutsetning i folkehelsesammenheng. Men det $\varnothing$ nskede nivå av pålitelighet er vanskelig å nå og å opprettholde. Det er viktig med klare og anvendelige definisjoner og et klassifikasjonssystem som uten store feilmarginer skiller selvmord fra andre dødsårsaker. Men det er viktigere med en god registrerings- og klassifiseringspraksis. Et kompetent og stabilt team med høy profesjonell integritet kan beskytte selvmordsstatistikken 
mot de ulike feilkildene den er så sårbar for. De ulike formene for kvalitetskontroll er helt klart en fordel når man søker å redusere antall feil.

Til tross for de mangler og den usikkerhet som er knyttet til selvmordsstatistikken, mener vi at disse er minimalisert i Norge. Norsk selvmordsstatistikk kan derfor brukes til de formål den er laget for. Men dette forutsetter at dagens kvalitet i det minste opprettholdes, og at de pågående anstrengelser for å forbedre statistikkens kvalitet blir videreført. Dette forutsetter igjen at de n $\varnothing$ dvendige ressurser blir avsatt til formålet, og at det gjøres regelmessige valideringsstudier.

\section{Referanser}

Beskow J. (1974.) "Tveksamhet" - ett problem vid klassifikation av självmord. Läkartidningen, 71: 2733-4.

Burrows, S., \& Laflamme, L. (2007). Assessment of accuracy of suicide mortality surveillance data in South Africa - Investigation in an urban setting. Crisis, 28(2): 74-81.

Clausen, T., Waal, H., Thoresen, M., \& Gossop, M. (2009). Mortality among opiate users: opioid maintenance therapy, age and causes of death. Addiction, 104(8):1356-1362.

De Leo, Dudley, M.J., Aebersold, C.J., Mendoza, J.A., Barnes, M.A., Harrison, J.E., \& Ranson, D.L. (2010). Achieving standardised reporting of suicide in Australia: rationale and program for change. Medical Journal of Australia, 192(8):452-456

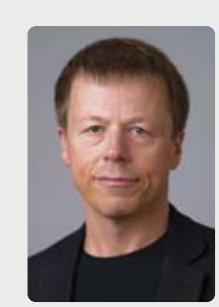

Lars Mehlum er psykiater og professor i suicidologi ved Univ. i Oslo. Han er leder for NSSF og er bredt engasjert $i$ en rekke forsknings- og forebyggingsprosjekter. Han har publisert flere lærebøker samt en rekke vitenskapelige artikler.

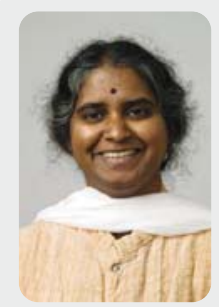

Latha Nrugham har vært ansatt som forsker ved NSSF siden 2008. Hun har publisert flere empiriske artikler og bokkapitler. Hun er i sluttfasen av sin doktorgrad fra NTNU med tema selvmordsfors $\varnothing \mathrm{k}$ blant ungdom. Nrugham har klinisk erfaring fra India og Norge og har arbeidet med gatebarn og -ungdom i Mumbai i mer enn 10 år.

Ekeberg, O., Jacobsen, D., Enger, E., Frederichsen, P., \& Holan L. (1985). The reliability of suicide statistics in Norway. Tidsskrift for Den norske lægeforening, 105(2):123-127.

Glattre, E., \& Blix, E. (1980). En vurdering av d $\varnothing$ dsårsaksstatistikken. Feil på d $\phi$ dsmeldingene. Rapporter 1992/8. Statistisk sentralbyrå.

Gjertsen, F. (1987). Selvmord i Norge. Institutt for sosiologi. Universitet i Oslo.

Grøholt, B., \& Ekeberg, Ø. (2003). Suicide in young people under 15 years: Problems of classification. Nordic Journal of Psychiatry, 57(6), 411-417.
Hess $\varnothing$, R. (1987). Routines and practices in the registration of suicide in Scandinavia. Acta Psychiatrica Scandinavica, 336 (76), 17-21.

Jobes, D.A., Berman, A.L., \& Josselson, A.R. (1987). Improving the validity and reliability of medico-legal certifications of suicide. Suicide and Life-Threatening Behavior, 17: 310-325.

Juel-Nielsen, N., \& Retterst $\varnothing 1$, N. (1987).

Preface. Acta Psychiatrica Scandinavica, 336 (76), 5-7.

Kolmos, L., \& Bach, E. (1987). Sources of error in the registration of suicide. Acta Psychiatrica Scandinavica, 336 (76), 22-41.

O'Carroll, P.W. (1989). A consideration of the validity and reliability of suicide mortality data. Suicide and Life-Threatening Behavior, 19, 1-16.

Phillips, D.P., \& Ruth, T.E. (1993). Adequacy of official suicide statistics for scientific research and public policy. Suicide and Life-Threatening Behavior, 23, 307-319.

Skrivarhaug, T., Bangstad, H.J., Stene, L.C., Sandvik, L., Hanssen, K.F., \& Joner, G. (2006). Long-term mortality in a nationwide cohort of childhood-onset type 1 diabetic patients in Norway. Diabetologia, 49(2):298-305

Speechley, M., \& Stavraky, K. 1991. The adequacy of suicide statistics for use in epidemiolog and public health. Canadian Journal of Public Health, 82, 38-42.

www.fhi.no

www.ssb.no

(Artikkelen er oversatt av Henning Herrestad.)

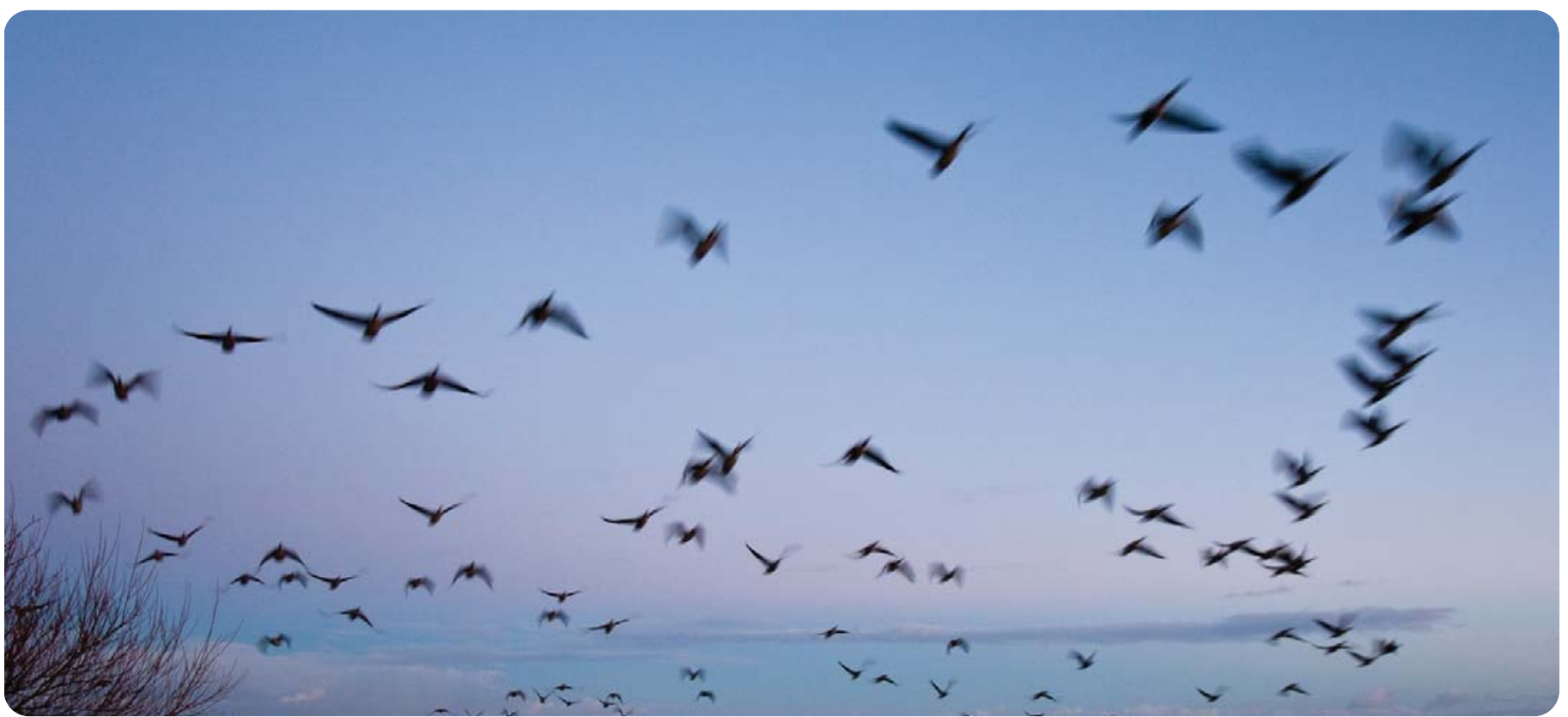

